\title{
CB2R induces a protective response for epileptic seizure via the PI3K 110 $\alpha$-AKT signaling pathway
}

\author{
QINGJUN CAO, XUEYAN LIU, FENGHUA YANG and HUA WANG
}

Department of Pediatrics, Shengjing Hospital of China Medical University, Shenyang, Liaoning 110004, P.R. China

Received May 7, 2017; Accepted May 11, 2018

DOI: $10.3892 /$ etm.2018.6788

\begin{abstract}
Epilepsy is a chronic brain disease caused by abnormal discharging in the brain, which induces momentary brain dysfunction. Cannabinoid 2 receptor (CB2R) is expressed in central nervous system (CNS) and serves an important role in the pathogenesis of CNS diseases. The aim of the present study was to explore the effects of CB2R activation on phosphoinositide 3-kinase (PI3K) 110 $\alpha$-protein kinase B (AKT) signaling in an astrocyte model of epilepsy. Rat CTX TNA2 astrocytes were treated with $\mathrm{Mg}$ free solution to establish a cell model of epilepsy and were subsequently treated with a CB2R agonist (JWH133) and antagonist (AM630). Cell cycle analysis revealed that treatment using $\mathrm{Mg}$ free solution inhibited cell cycle transition. JWH133 facilitated cell cycle progression while AM630 inhibited it. Western blotting results demonstrated that treatment with $\mathrm{Mg}$ free solution downregulated the expression of cyclin D1, cyclin E, phosphorylated Retinoblastoma (p-Rb), B-cell lymphoma 2 (Bcl-2), PI3K $110 \alpha$, p-AKT and p-mammalian target of rapamycin, whereas JWH133 treatment upregulated these proteins. AM630 ameliorated the JWH133-induced upregulation of these proteins. To confirm the involvement of AKT signaling, the AKT inhibitor wortmannin was used. The results revealed that wortmannin inhibited the effect of JWH133 on p-AKT, cyclin D1, p-Rb and Bcl-2 expression. In addition, the effects of JWH133 and AM630 on PI3K $110 \alpha$-AKT signaling were verified using a rat model of epilepsy. In conclusion, the present study demonstrates that CB2R activation induces astrocyte proliferation and survival via activation of the PI3K $110 \alpha$-AKT signaling pathway.
\end{abstract}

\section{Introduction}

Epilepsy is a common type of neurological disorder hallmarked by over-synchronization of neurons in the brain (1-3).

Correspondence to: Dr Hua Wang, Department of Pediatrics, Shengjing Hospital of China Medical University, 36 San Hao Street, Shenyang, Liaoning 110004, P.R. China

E-mail: tvzhzt@163.com

Key words: epilepsy, cannabinoid 2 receptor, astrocyte, protein kinase B
Epileptic electrical disturbances are associated with abnormalities in behavior, awareness, sensation and movement (4-10). According to reports, 5-8\% of the population suffers from epilepsy and $60 \%$ of cases occur in childhood or infancy (11-13).

It is known that astrocytes provide support for neurons via a variety of mechanisms (14). Insufficient support may lead to alterations in neuronal function, which results in seizures. Clearance and transport of glutamate is another neuroprotective function of astrocytes, the loss of which serves an important role in epilepsy development (15). Disturbances in the ion hemostasis of astrocytes may also result in seizures (16-18). Furthermore, astrocytes are capable of direct communication with neurons at the synapse $(19,20)$. Together, these previous studies indicate that loss of astrocyte function is associated with epilepsy development and that maintaining astrocyte hemostasis is important for epilepsy prevention.

Recently, the role of the cannabinoid system in epilepsy has been explored (21). The cannabinoid system comprises cannabinoid receptors (CBRs), cannabinoid (endocannabinoid) and the enzymes that regulate the synthesis and degradation of endocannabinoids (21). There are two subtypes of CBR: CB1R and CB2R. CB2R was first isolated from human bone marrow cells and was thought to exist in the peripheral immune system, whereas CB1R was generally considered to exist in the central nervous system (CNS). Recent reports have demonstrated that that $\mathrm{CB} 2 \mathrm{R}$ also serves an important role in the nervous system (22). It has been reported that $\mathrm{CB} 2 \mathrm{R}$ potentiates the antiepileptic action of $\mathrm{CB}$ agonists via the cGMP signaling pathway in a model of hippocampal seizures (23). However, the biological effects and exact mechanism of CB2R during the development of epilepsy is not well understood. The aim of the present study was to explore the biological effects and mechanisms of $\mathrm{CB} 2 \mathrm{R}$ activation in astrocyte and rat models of epilepsy.

\section{Materials and methods}

Preparation of the epileptiform cell model. CTX TNA2 rat astrocytes were purchased from American Type Culture Collection (Manassas, VA, USA) and cultured in Dulbecco's modified Eagle's medium (DMEM; Invitrogen; Thermo Fisher Scientific, Inc., Waltham, MA, USA) containing 10\% heat-inactivated fetal bovine serum (Invitrogen; Thermo Fisher Scientific, Inc.), $100 \mathrm{U} / \mathrm{ml}$ penicillin and $100 \mu \mathrm{g} / \mathrm{ml}$ 
streptomycin at $37^{\circ} \mathrm{C}$ in a humidified atmosphere containing $5 \% \mathrm{CO}_{2}$. Cells were passaged every 2 days with $0.25 \%$ trypsin.

To establish epileptiform activity, cells were placed in $\mathrm{Mg}$ free medium (145 mM NaCl, $2.5 \mathrm{mM} \mathrm{KCl,} 10 \mathrm{mM}$ HEPES, $2 \mathrm{mM} \mathrm{CaCl} 2,10 \mathrm{mM}$ glucose, and $0.002 \mathrm{mM}$ glycine, $\mathrm{pH} 7.3$, adjusted to $325 \mathrm{mOsm}$ with sucrose) for $3 \mathrm{~h}$ at $37^{\circ} \mathrm{C}$ in a humidified atmosphere containing 5\% $\mathrm{CO}_{2}$. CB2R agonist (JWH133, $4 \mu \mathrm{M}$; R \& D Systems, Inc., Minneapolis, MN, USA), CB2R antagonist (AM630, $1 \mu \mathrm{M}$ ) and AKT inhibitor (wortmannin, $2 \mu \mathrm{M}$; R\&D Systems, Inc.) were administered for $24 \mathrm{~h}$ at $37^{\circ} \mathrm{C}$ in a humidified atmosphere containing $5 \% \mathrm{CO}_{2}$.

Pilocarpine-induced status epilepticus (SE) in rats. The present study was approved by the Institutional Ethical Review Boards of the Shengjing Hospital of China Medical University (Shenyang, China). Male Sprague-Dawley rats had access to food and water ad libitum. All the rats were used following university animal care and use protocols. A total of 40 male Sprague-Dawley rats (age, 20 days; weight, 100-120 g) were purchased from the Department of Experimental Animals, Shengjing Hospital of China Medical University. Rats were housed in single cages with a 12-h light/dark cycle at $25^{\circ} \mathrm{C}$ and $50 \%$ humidity. Rats were divided into four different groups: Control group, SE group, CB2R agonist group and $\mathrm{CB} 2 \mathrm{R}$ antagonist group. At $30 \mathrm{~min}$ prior to pilocarpine injections, rats were administered with methylscopolamine nitrate (S8502-1G; Sigma-Aldrich; Merck KGaA, Darmstadt, Germany; $1 \mathrm{mg} / \mathrm{kg}$ i.p.) to minimize the peripheral parasympathetic effects of pilocarpine treatment. Pilocarpine nitrate (P6503-5G; Sigma-Aldrich; Merck KGaA; 375 mg/kg i.p.) was subsequently administered. Onset of SE typically occurred 20-40 min following the pilocarpine injection when the animal displayed continuous moderate to severe behavioral seizures characterized by forelimb clonus, rearing, and falling. The CB2R agonist (JWH133, $1.5 \mathrm{mg} / \mathrm{kg}$ ) was administered every $6 \mathrm{~h}$ following termination of seizure activity in the agonist group. The CB2R antagonist (AM630, $1 \mathrm{mg} / \mathrm{kg}$ ) was administered every $6 \mathrm{~h}$ following termination of seizure activity in the antagonist group.

SE was defined as continuous seizure activity lasting $\geq 30$ min or intermittent seizures without regaining consciousness between seizures lasting $\geq 30 \mathrm{~min}$ (24). The severity of convulsions was evaluated and only the rats that displayed behaviors consistent with ongoing SE were used in the present study. Seizure activity was terminated by consecutive diazepam (Shanghai Xudong Haipu Pharmaceutical Co., Ltd., Shanghai, China) injections (5 mg/kg i.p., solubilized in $10 \%$ ethanol, $45 \%$ propylene glycol and $45 \% \mathrm{H}_{2} \mathrm{O}$ ) at 1,3 , and $5 \mathrm{~h}$ post onset of SE. Control groups were composed of naive and sham control rats that received methylscopolamine nitrate and diazepam injections only. Rats were sacrificed at $24 \mathrm{~h}$ after termination of SE. Hippocampus tissue was isolated and frozen at $-80^{\circ} \mathrm{C}$.

Western blotting. Total proteins were extracted from frozen hippocampus tissue and cells using lysis buffer (P0013B; Beyotime Institute of Biotechnology, Haimen, China) and quantified using the Bradford method. Proteins (30 $\mu \mathrm{g}$ per lane) were separated using SDS-PAGE (6\% gels) after denaturation by mixing with the loading buffer at a ratio of 1:4 for $5 \mathrm{~min}$ at $100^{\circ} \mathrm{C}$. SDS-PAGE was run at $120 \mathrm{~V}$ until the dye reached the bottom of the separation gel, and the proteins were then transferred to a polyvinylidene fluoride membrane (EMD Millipore, Billerica, MA, USA) using wet electroblotting at $120 \mathrm{~V}$ for $2 \mathrm{~h}$. The membrane was blocked with $5 \%$ skimmed milk powder for $2 \mathrm{~h}$, then washed three times with Tris-buffered saline plus Tween-20 (15 min/wash). Membranes were incubated overnight at $4^{\circ} \mathrm{C}$ with rabbit monoclonal antibodies against B-cell lymphoma 2 (Bcl-2; 1:1,000; cat. no. 3498), phosphorylated Retinoblastoma (p-Rb; 1:1,000; cat. no. 8147), phosphoinositide 3 kinase (PI3K) 110 $\alpha$ (1:1,000; cat. no.), p-mammalian target of rapamycin (mTOR; 1:1,000; cat. no. 2971), mTOR (1:1,000; cat. no. 2972), glial fibrillary acidic protein (GFAP; 1:1,000; cat. no. 3670, ), p-AKT (1:1,000; cat. no. 9271) AKT (1:1,000; cat. no. 9272) cyclin D1 (1:1,000; cat. no. 2978) cyclin E (1:1,000; cat. no. 20808; all Cell Signaling Technology, Inc., Danvers, MA, USA), $\beta$-actin (1:1,000; sc-47778) and GAPDH (1:1,000; sc-47724; both Santa Cruz Biotechnology, Dallas, TX, USA). Subsequently, samples were incubated with peroxidase-coupled anti-mouse monoclonal antibodies (1:1,000; cat. no. 7076, Cell Signaling Technology, Inc.) or rabbit IgG antibodies (1:1,000; cat. no. 7074, Cell Signaling Technology, Inc.) at $37^{\circ} \mathrm{C}$ for $2 \mathrm{~h}$. Target proteins on the were visualized using a Pierce enhanced chemiluminescence kit (Thermo Fisher Scientific, Inc.) and captured using a DNR BioImaging system (DNR Bio-Imaging Systems, Jerusalem, Israel). Protein densitometry was evaluated using Tecan Infinite 200 PRO NanoQuant (Tecan Group Ltd., Mannedorf, Switzerland).

Flow cytometry for cell cycle analysis. Cells $(50,000)$ in 6 -well plates were harvested $48 \mathrm{~h}$ after intervention by $0.25 \%$ trypsin. Cells were washed twice with chilled PBS and resuspended in $250 \mu \mathrm{l}$ of binding buffer (10010049; Gibco; Thermo Fisher Scientific, Inc.), adjusted to $1 \times 10^{6}$ cells $/ \mathrm{ml}$ and fixed in $1 \%$ paraformaldehyde at $4^{\circ} \mathrm{C}$. Cells were stained with $5 \mathrm{mg} / \mathrm{ml}$ propidium iodide for $30 \mathrm{~min}$ at room temperature for cell cycle analysis. Following the incubation, cells were analyzed using a FACSCalibur flow cytometer (BD Biosciences, Franklin Lakes, NJ, USA).

Statistical analysis. SPSS version 16 for Windows (SPSS, Inc., Chicago, IL, USA) was used for all statistical analyses. Student's t-test was used to compare data between control and treatment groups. One-way analysis of variance with Bonferroni's post hoc test was used to compare the means of two or more groups. All P-values were based on a two-sided statistical analysis and $\mathrm{P}<0.05$ was considered to indicate a statistically significant difference.

\section{Results}

Treatment with CB2R agonist/antagonist changes cell cycle transition in rat astrocytes. Flow cytometry was performed to examine the biological effects of CB2R on cell cycle transition. The percentage of cells in the $\mathrm{S}$ phase was decreased in astrocytes treated with $\mathrm{Mg}$ free solution whereas the percentage in the G1 phase was increased $(\mathrm{P}<0.05$; Fig. 1). This suggested that G1-S transition in astrocytes was inhibited during epilepsy. Treatment with the CB2R agonist JWH133 significantly upregulated the percentage of cells in $\mathrm{S}$ phase 

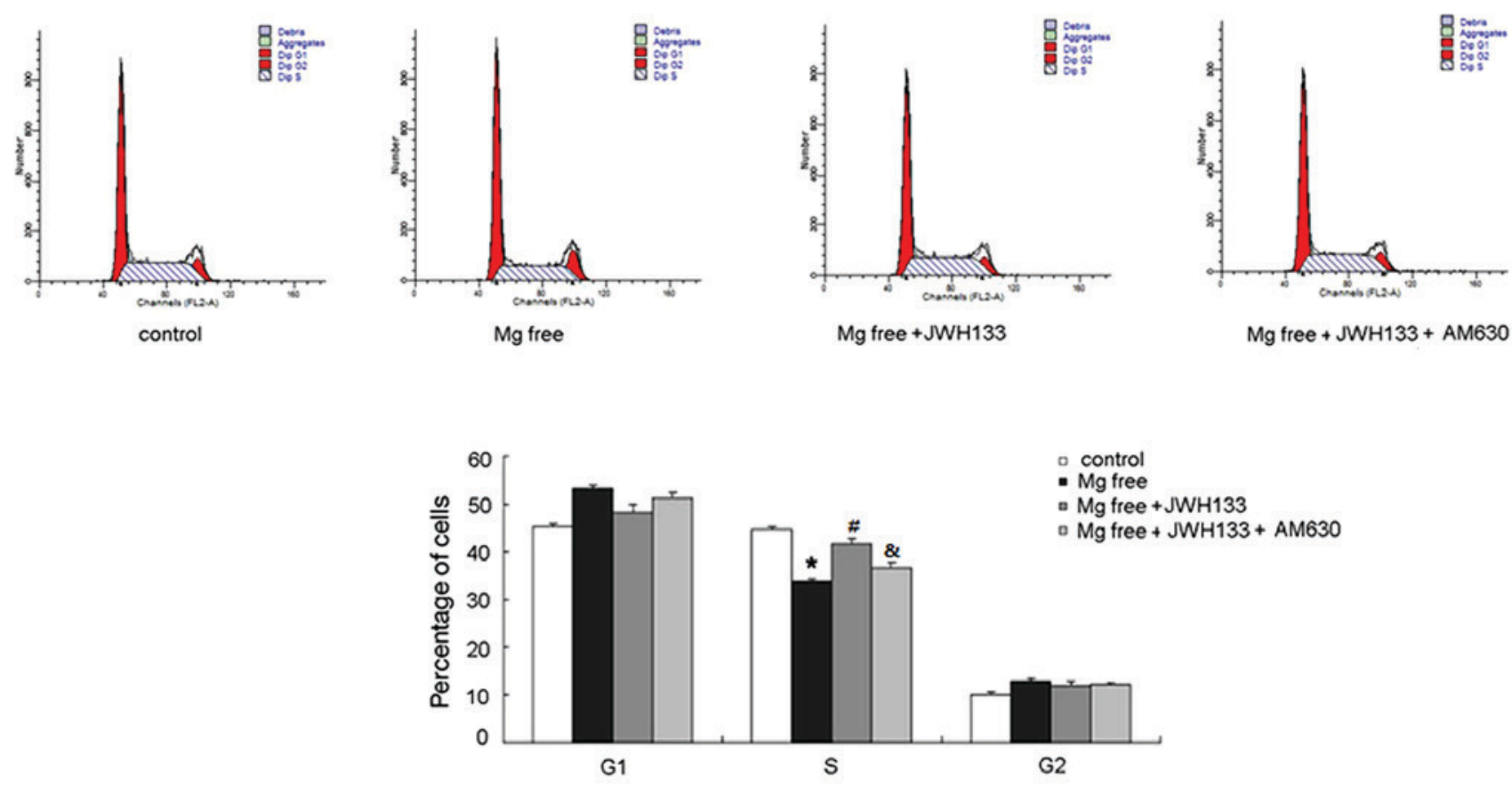

Figure 1. Flow cytometry analysis revealed that CB2R regulates G1-S cell cycle transition. The percentage of cells increased in G1 and decreased in S phase when treated with Mg free solution alone or in conjunction with JWH133 and AM630. G1 percentage decreased and S percentage increased when treated with Mg free solution compared with control group. Treatment with JWH133 significantly upregulated the percentage of cells in S phase and reduced the number of G1 phase cells compared with Mg free solution. AM630 administration suppressed G1 to S transition in astrocytes compared with the Mg free solution + JWH133. ${ }^{*} \mathrm{P}<0.05$ vs. control group; ${ }^{\mathrm{P}} \mathrm{P}<0.05$ vs. Mg free solution; ${ }^{\circledR} \mathrm{P}<0.05$ vs. Mg free solution + JWH133. CB2R, cannabinoid 2 receptor.

$(\mathrm{P}<0.05)$ and reduced the number of G1 phase cells (Fig. 1) compared with the group treated with $\mathrm{Mg}$ free solution. AM630 administration ameliorated the effects of JWH133, suppressing G1 to $\mathrm{S}$ transition in astrocytes compared with the $\mathrm{Mg}$ free solution + JWH133 ( $<<0.05$; Fig. 1).

CB2R agonist/antagonist alters the expression of cell cycle related proteins. $\mathrm{p}-\mathrm{Rb}$, cyclin $\mathrm{D} 1$, cyclin $\mathrm{E}$ and $\mathrm{Bcl}-2$ protein expression was determined using western blotting. The expression of $\mathrm{p}-\mathrm{Rb}$, cyclin $\mathrm{D} 1$ and cyclin $\mathrm{E}$ decreased significantly when cells were treated with $\mathrm{Mg}$ free solution compared with the control group $(\mathrm{P}<0.05)$. The expression of $\mathrm{Bcl}-2$ in astrocytes treated with $\mathrm{Mg}$ free solution was slightly lower than compared with the control (Fig. 2). Administration of the CB2R agonist JWH133 increased p-Rb, cyclin D1, cyclin E and $\mathrm{Bcl}-2$ protein expression compared with $\mathrm{Mg}$ free solution alone $(\mathrm{P}<0.05)$, whereas the addition of the $\mathrm{CB} 2 \mathrm{R}$ antagonist (AM630) effectively suppressed the expression of $p-R b$, cyclin D1, cyclin E and Bcl-2 compared with the $\mathrm{Mg}$ free solution + JWH133 ( $<<0.05$; Fig. 2).

$C B 2 R$ regulates the $A K T$ signaling pathway in rat astrocytes. To clarify the potential mechanism of the $\mathrm{CB} 2 \mathrm{R}$ agonist/antagonist, several signaling pathways were assessed and it was observed that changes in PI3K $110 \alpha$-AKT activity were associated with changes in cell cycle protein expression. The expression of p-AKT and p-mTOR was significantly decreased in astrocytes treated with $\mathrm{Mg}$ free serum compared with control astrocytes $(\mathrm{P}<0.05$; Fig. 3). Administration of the CB2R activator JWH133 caused a significant increase in $\mathrm{p}-\mathrm{AKT} / \mathrm{AKT}$ and $\mathrm{p}-\mathrm{mTOR} / \mathrm{mTOR}$ compared with the Mg free solution alone $(\mathrm{P}<0.05$; Fig. 3). When treated with the $\mathrm{CB} 2 \mathrm{R}$ inhibitor AM630, levels of p-AKT/AKT and p-mTOR/mTOR declined significantly compared with the $\mathrm{Mg}$ free solution + JWH133 group ( $\mathrm{P}<0.05$; Fig. 3). The expression of PI3K $110 \alpha$ p110 was also assessed and followed a similar trend to p-AKT; however, no statistically significant differences were observed (Fig. 3).

Blocking the AKT pathway abolishes the effects of the $C B 2 R$ agonist/antagonist in rat astrocytes. To confirm that AKT signaling serves a role in altering cell cycle distribution, the AKT inhibitor wortmannin was used. Wortmannin treatment significantly downregulated p-AKT expression, indicating that the AKT pathway was successfully blocked $(\mathrm{P}<0.05$; Fig. 4). The level of p-AKT, p-Rb, cyclin D1 and $\mathrm{Bcl}-2$ expression was upregulated by activation of $\mathrm{CB} 2 \mathrm{R}$ compared with the control group (JWH133 treatment; $\mathrm{P}<0.05$; Fig. 4). However, wortmannin blocked the effects of JWH133 on these proteins. In the group treated with $\mathrm{Mg}$ free + JWH133 + wortmannin, p-AKT, p-Rb, cyclin D1 and Bcl-2 expression decreased significantly compared with the $\mathrm{Mg}$ free + JWH133 group $(\mathrm{P}<0.05$; Fig. 4$)$. In the group treated with $\mathrm{Mg}+$ wortmannin, $\mathrm{p}-\mathrm{AKT}, \mathrm{p}-\mathrm{Rb}$, cyclin D1 and $\mathrm{Bcl}-2$ expression was significantly decreased compared with the $\mathrm{Mg}$ free group $(\mathrm{P}<0.05$; Fig. 4). No significant difference in the expression of $\mathrm{p}-\mathrm{AKT}, \mathrm{p}-\mathrm{Rb}$, cyclin $\mathrm{D} 1$ and $\mathrm{Bcl}-2$ was observed between the Mg free + JWH133 + wortmannin and $\mathrm{Mg}+$ wortmannin groups (Fig. 4). These results suggest that CB2R activation by JWH133 upregulates p-Rb, cyclin D1 and Bcl-2 via the AKT signaling pathway.

$C B 2 R$ regulates the PI3K $110 \alpha-A K T$ signaling pathway in a rat model of epilepsy. To further investigate the role of 


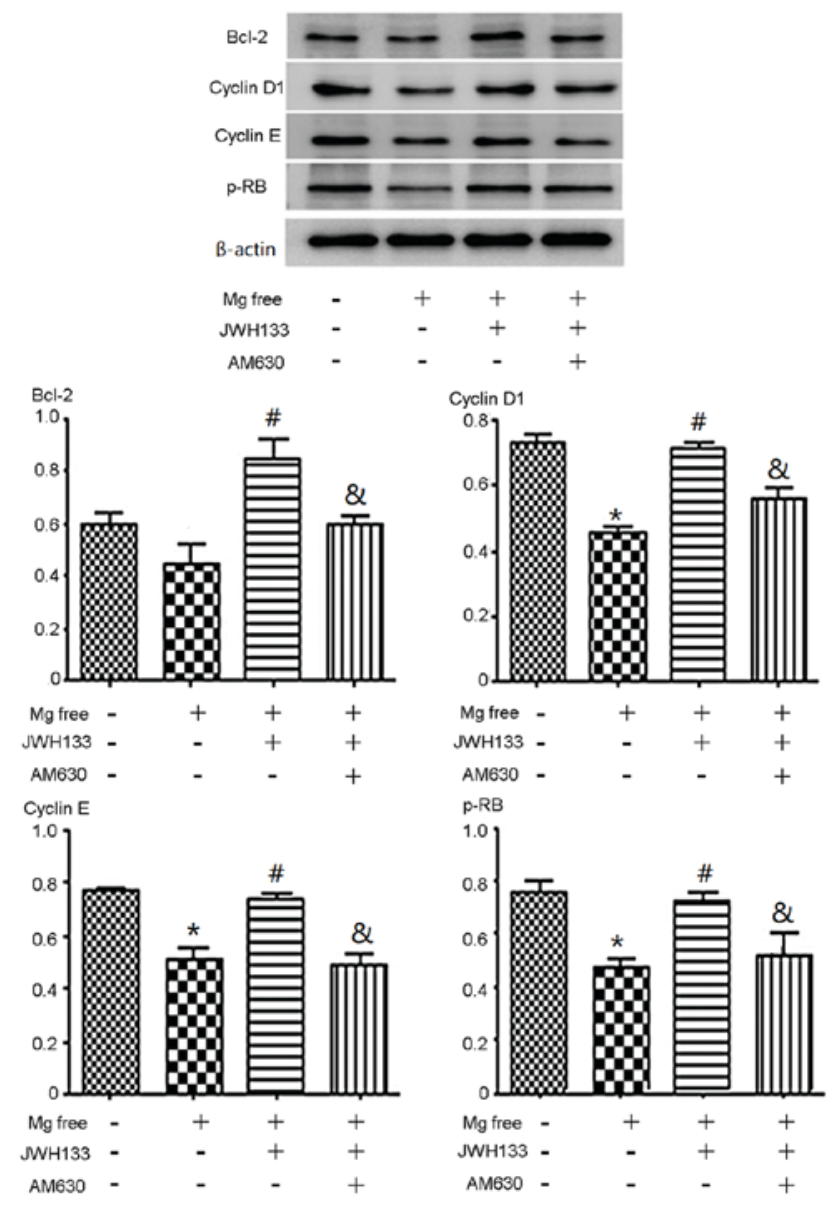

Figure 2. Effects of CB2R agonist/antagonist on cell cycle-associated protein expression. The expression of cyclin D1, cyclin E and $\mathrm{p}-\mathrm{Rb}$ decreased when cells were treated with $\mathrm{Mg}$ free solution alone or co-administered with JWH133 and AM630. The expression of p-Rb, cyclin D1 and cyclin E decreased significantly when cells were treated with $\mathrm{Mg}$ free solution compared with the control group. The expression of $\mathrm{Bcl}-2$ in astrocytes treated with $\mathrm{Mg}$ free solution was slightly lower compared with the control. JWH133 increased $\mathrm{p}-\mathrm{Rb}$, cyclin $\mathrm{D} 1$, cyclin $\mathrm{E}$ and $\mathrm{Bcl}-2$ protein expression compared with with $\mathrm{Mg}$ free solution alone. AM630 decreased the expression of $\mathrm{p}-\mathrm{Rb}$, cyclin D1, cyclin E and Bcl-2 compared with the Mg free solution + JWH133. ${ }^{*} \mathrm{P}<0.05$ vs. control group; $\mathrm{P}<0.05$ vs. $\mathrm{Mg}$ free solution; ${ }^{\circledR} \mathrm{P}<0.05$ vs. $\mathrm{Mg}$ free solution + JWH133. CB2R, cannabinoid 2 receptor; $\mathrm{p}$-, phosphorylated; $\mathrm{Rb}$, retinoblastoma; Bcl-2, B-cell lymphoma 2.

CB2R in regulating the PI3K $110 \alpha-$ AKT signaling pathway, CB2R agonist/antagonists were administered to rats with pilocarpine-induced epilepsy. The expression of p-AKT and PI3K $110 \alpha$ was significantly decreased in rats with epilepsy compared with the control group $(\mathrm{P}<0.05$; Fig. 5). p-AKT and PI3K $110 \alpha$ expression was significantly increased in rats treated with the CB2R agonist JWH133 compared with rats treated with pilocarpine alone $(\mathrm{P}<0.05$; Fig. 5). When rats with epilepsy were treated with the CB2R antagonist AM630, p-AKT expression was significantly reduced compared with agonist JWH133 (P<0.05; Fig. 5). The expression of PI3K $110 \alpha$ in the AM630 group was markedly reduced compared with the JWH133 group ( $\mathrm{P}<0.05$; Fig. 5). The expression of GFAP, the biomarker of astrocytes (25), was also assessed. The CB2R agonist JWH133 effectively promoted GFAP expression $(\mathrm{P}<0.05$; Fig. 5). However, administration of the CB2R antagonist AM630 reduced the expression of GFAP compared with the JWH133 group (P<0.05: Fig. 5).
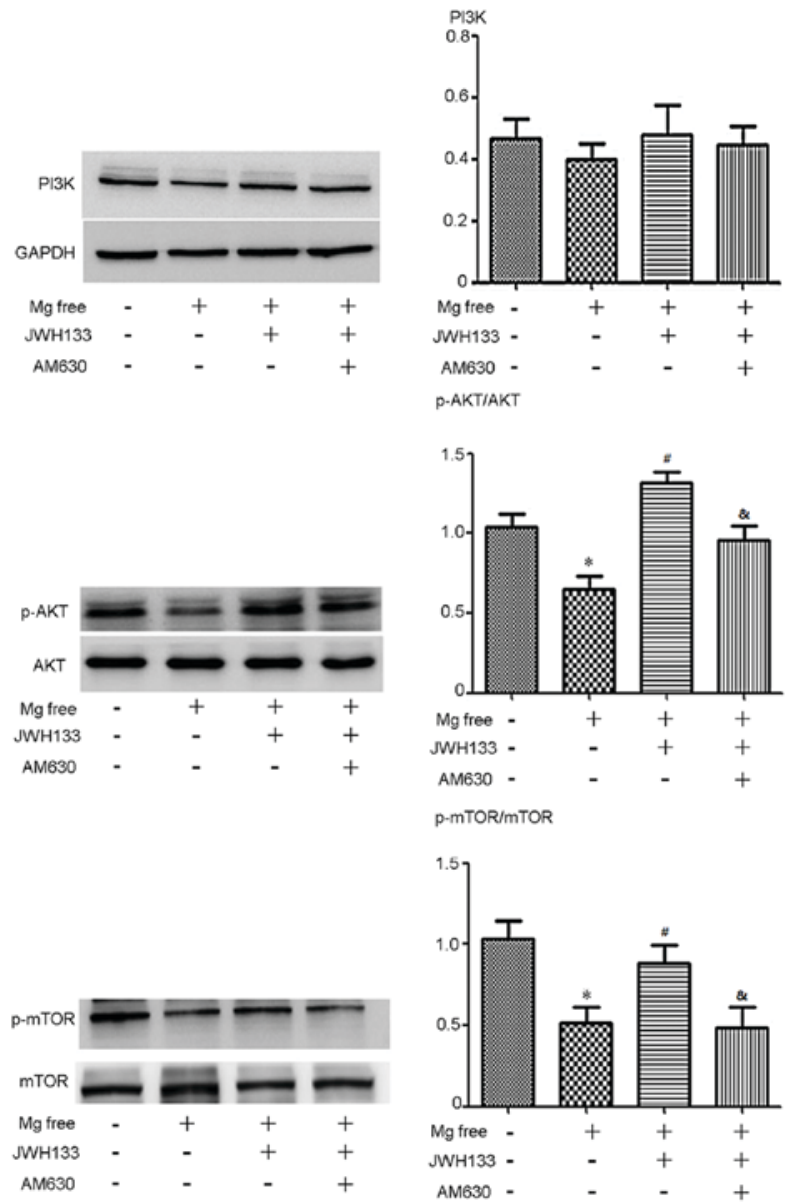

Figure 3. CB2R regulates the PI3K $110 \alpha-A K T$ signaling pathway. The expression of p-AKT/AKT and p-mTOR/mTOR was decreased when cells were treated with $\mathrm{Mg}$ free solution alone compared with the control group. JWH133 caused a significant increase in p-AKT/AKT and p-mTOR/mTOR compared with Mg free solution alone. AM630 decreased levels of p-AKT/AKT and p-mTOR/mTOR significantly compared with the $\mathrm{Mg}$ free solution + JWH133 group. ${ }^{*} \mathrm{P}<0.05$ vs. control group; ${ }^{\prime} \mathrm{P}<0.05$ vs. $\mathrm{Mg}$ free solution; ${ }^{\circledR} \mathrm{P}<0.05$ vs. Mg free solution + JWH133. CB2R, cannabinoid 2 receptor; PI3K, phosphoinositide 3 kinase; AKT, protein kinase B; p-, phosphorylated; mTOR, mammalian target of rapamycin.

\section{Discussion}

Epilepsy is a common and complex disorder of the CNS, the mechanism of which remains to be elucidated. The pathogenesis of epilepsy is considered to be associated with dysfunctional ion channels, neurotransmitters and glial cells (26-28). The cannabinoid system comprises the cannabinoid receptor, cannabinoids and enzymes. There are two types of cannabinoid receptor, CB1R and CB2R, of which CB2R exists in the CNS, including the cerebral cortex, corpus callosum, hippocampus, basal ganglia region and opisthencephalon. Previous reports have demonstrated that cannabinoid may relieve the symptoms of epilepsy in animal models, suggesting a potential link between CB2R and epilepsy (29,30).

Astrocytes are the main type of glial cell in the CNS and they provide support and protection for neurons (31). Astrocytes supply neurons with nutrients, oxygen and cytokines and maintain homeostasis. Astrocyte dysfunction has been reported to be associated with the development of epilepsy; for example, disturbances in astrocyte ion hemostasis result 


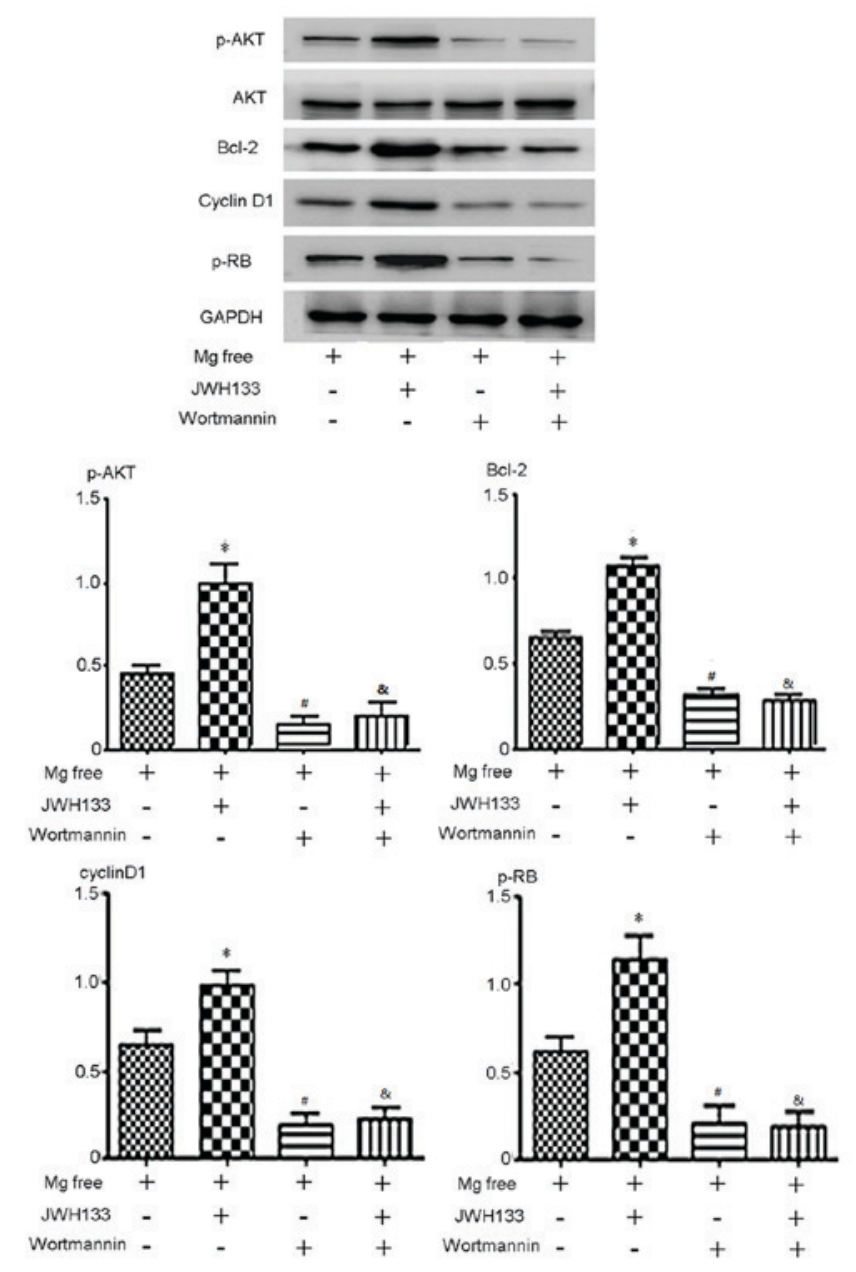

Figure 4. Expression of $\mathrm{p}-\mathrm{AKT}, \mathrm{AKT}, \mathrm{p}-\mathrm{Rb}$, cyclin $\mathrm{D} 1$ and $\mathrm{Bcl}-2$ protein in cells treated with the PI3K $110 \alpha$-AKT inhibitor wortmannin. p-AKT, AKT p-Rb, cyclin D1 and Bcl-2 were downregulated when cells were treated with $\mathrm{Mg}$ free solution and wortmannin, with or without JWH133. The level of p-AKT, p-Rb, cyclin D1 and Bcl-2 expression was upregulated by JWH133 compared with the $\mathrm{Mg}$ free group. In the group treated with $\mathrm{Mg}$ + wortmannin, p-AKT, $\mathrm{p}-\mathrm{Rb}$, cyclin $\mathrm{D} 1$ and $\mathrm{Bcl}-2$ expression decreased significantly compared with $\mathrm{Mg}$ free. In the group treated with $\mathrm{Mg}+\mathrm{JWH} 133$ + wortmannin, p-AKT, $\mathrm{p}-\mathrm{Rb}$, cyclin $\mathrm{D} 1$ and $\mathrm{Bcl}-2$ expression decreased significantly compared with $\mathrm{Mg}+\mathrm{JWH133}$. ${ }^{*} \mathrm{P}<0.05$ vs. Mg free group; ${ }^{*} \mathrm{P}<0.05$ vs. $\mathrm{Mg}$ free; ${ }^{\mathrm{k}} \mathrm{P}<0.05 \mathrm{vs}$. $\mathrm{Mg}$ free solution + JWH133. p-, phosphorylated; AKT, protein kinase B; Rb, retinoblastoma; Bcl-2, B-cell lymphoma 2.

in seizures (15). Astrocytes are able to communicate directly with neurons at the synapse to control the ion channel function of neurons $(19,20)$. Maintaining astrocyte function may therefore be important for protecting against epilepsy.

In the present study, changes in cell cycle distribution induced by the epileptic microenvironment and the potential underlying mechanisms were investigated. Flow cytometry analysis revealed that $\mathrm{G} 1$ to $\mathrm{S}$ transition was inhibited when cells were treated with $\mathrm{Mg}$ free solution. The CB2R agonist JWH133 successfully upregulated the percentage of cells in S phase and downregulated the percentage of G1 phase cells, demonstrating that JWH133 promotes G1 to S transition. However, the CB2R antagonist AM630 abolished these effects. These results suggest that $\mathrm{CB} 2 \mathrm{R}$ regulates cell cycle transition in astrocytes.

In addition, it was determined that the expression of cell cycle-associated proteins was altered in accord with cell cycle changes. Bcl-2, p-Rb, cyclin D1 and cyclin Eexpression decreased
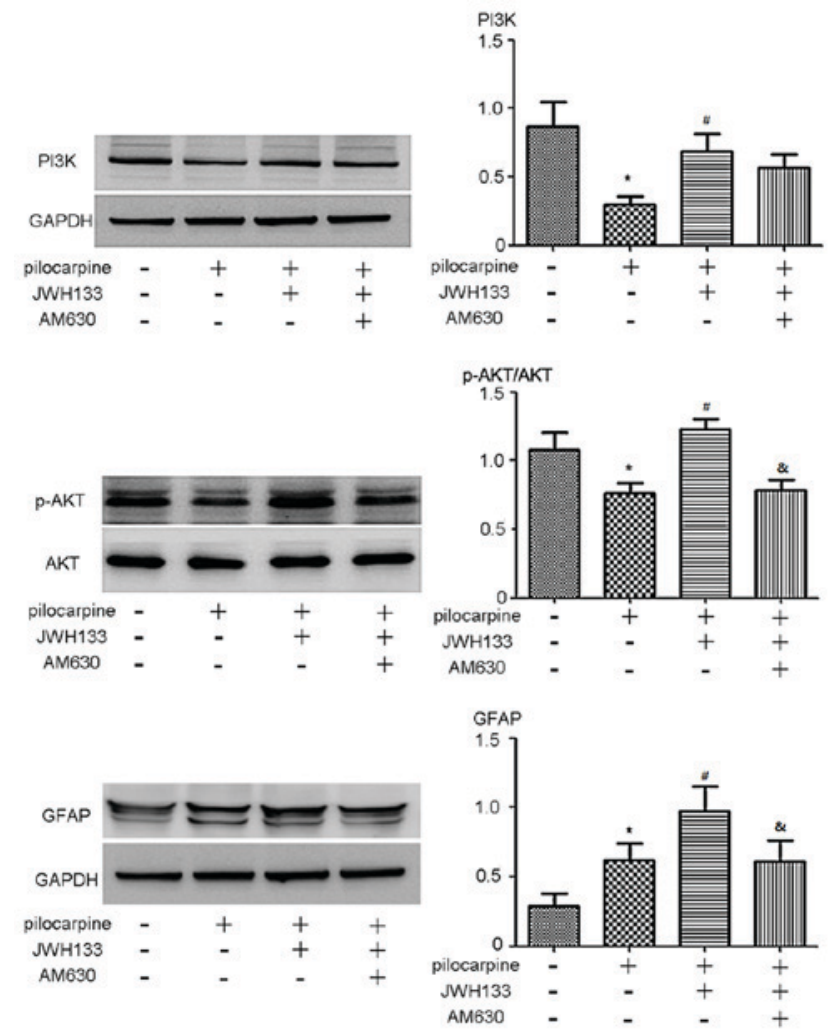

Figure 5. CB2R regulates PI3K $110 \alpha, \mathrm{p}-\mathrm{AKT}$ and GFAP expression in a rat model of epilepsy. The levels of p-AKT and PI3K $110 \alpha$ were significantly decreased in rats with epilepsy compared with the control group. JWH133 upregulated the p-AKT and PI3K $110 \alpha$ expression significantly compared with rats treated with pilocarpine alone. AM630 decreased the level of p-AKT expression compared with JWH133. "P<0.05 vs. control group; ${ }^{\text {} P} \mathrm{P}<0.05$ vs. pilocarpine alone; ${ }^{\circledR} \mathrm{P}<0.05$ vs. pilocarpine $+\mathrm{JWH} 133$. CB2R, cannabinoid 2 receptor; PI3K, phosphoinositide 3 kinase; p-, phosphorylated; AKT, protein kinase B; GFAP, glial fibrillary acidic protein.

when cells were treated with $\mathrm{Mg}$ free solution. The CB2R agonist JWH133 enhanced the expression of p-Rb, cyclin D1, cyclin E and Bcl-2, whereas the CB2R antagonist AM630 suppressed the expression of $\mathrm{p}-\mathrm{Rb}$, cyclin $\mathrm{D} 1$, cyclin $\mathrm{E}$ and $\mathrm{Bcl}-2$. It has previously been reported that the CB2R activator JWH-015 reduced neuron loss and cytochrome $\mathrm{C}$ release to improve the biological function of nerves, an effect that was reversed using the CB2R inhibitor SR 144528 (32). The results of the present study support those of previous studies, suggesting CB2R activation protects astrocytes and promotes astrocyte growth.

Several signaling pathways were assessed to clarify the potential mechanism of biological effects induced by CB2R agonist/antagonist. The results indicated that PI3K-AKT signaling was responsible for the changes in cell cycle protein expression. PI3K-AKT signaling comprises PI3K 110 $\alpha$, AKT and downstream proteins. Second-messenger phosphatidylinositol $(3,4,5)$-trisphosphate was generated following the activation of PI3K $110 \alpha$, which in turn activated AKT phosphorylation. PI3K-AKT activation is associated with neuronal activities, including proliferation, apoptosis, differentiation and metabolism (33). PI3K-AKT dysregulation is critical in the development of CNS diseases, including Parkinson's Disease, ischemic brain injury and epilepsy (34-36). In the present study it was demonstrated that p-AKT expression decreased significantly in astrocytes in an epileptic environment. CB2R 
activator JWH133 promoted p-AKT expression, whereas the CB2R inhibitor AM630 inhibited it. Changes in the expression of PI3K p110 were similar to p-AKT in these groups. mTOR is a downstream protein of AKT signaling which has been reported to be associated with the development of epilepsy (37-41). It was reported that mTOR serves an important role in epileptic seizures via adjusting the excitability of dentate gyrus gramular cells (37). p-mTOR expression decreased significantly in astrocytes in the epileptic microenvironment. The CB2R activator JWH133 elevated the ratio of p-mTOR/mTOR while CB2R inhibitor AM630 reduced it. These results suggest that activating CB2R induces AKT signaling.

The AKT inhibitor wortmannin was used to investigate the role of AKT signaling in CB2R-induced cell cycle changes and it was demonstrated that levels of p-AKT, p-Rb, cyclin D1 and $\mathrm{Bcl}-2$ were upregulated by CB2R activation in astrocytes without wortmannin treatment. However, wortmannin blocked the effects of JWH133 on these proteins. In wortmannin treated cells, no significant differences in $\mathrm{p}-\mathrm{Rb}$, cyclin $\mathrm{D} 1$ and $\mathrm{Bcl}-2$ were observed between the Mg free and JWH133 groups. These results suggest that JWH133-induced CB2R activation upregulates $\mathrm{p}-\mathrm{Rb}$, cyclin $\mathrm{D} 1$ and $\mathrm{Bcl}-2$ via the AKT signaling pathway. It has been reported that AKT phosphorylation accelerates its degradation $(42,43)$. In addition, the p-AKT/AKT ratio was measured in the current study and it was identified that JWH133 significantly upregulated AKT phosphorylation. Wortmannin suppressed the PI3K signal pathway and p-AKT/AKT ratio was depressed even following JWH133 treatment.

To further investigate the regulatory role of $\mathrm{CB} 2 \mathrm{R}$ in the PI3K/AKT signaling pathway, a rat model of epilepsy was established and treated with CB2R agonist/antagonists. The expression of p-AKT and PI3K $110 \alpha$ expression was significantly decreased in rats with epilepsy compared with control rats and treatment with the CB2R agonist JWH133 significantly promoted AKT and PI3K $110 \alpha$ expression. Rats treated with the CB2R antagonist AM630 had significantly lower p-AKT levels and PI3K $110 \alpha$ expression was markedly downregulated compared with rats treated with JWH133. These results are similar to the findings of the in vitro experiments. GFAP expression was also assessed to investigate the level of astrogliosis and astrocyte viability. The results revealed that treatment with CB2R agonist JWH133 upregulated GFAP expression and treatment with the CB2R antagonist AM630 downregulated GFAP expression in comparison. These results suggest that, in a rat model of epilepsy, CB2R activation may enhance astrocyte viability and activate AKT signaling.

In conclusion, the results of the present study demonstrate that CB2R activation upregulates the proliferation of rat astrocytes in vivo and in vitro, possibly via activation of the PI3K-AKT signaling pathway.

\section{Acknowledgements}

Not applicable.

\section{Funding}

The present study was supported by the Liaoning Science and Technology Department of China Project (grant. no. 2014225007).

\section{Availability of data and materials}

All data generated or analyzed during this study are included in this published article.

\section{Authors' contributions}

QC performed the western blot experiments and wrote the manuscript. XL performed the flow cytometry experiments. FY constructed the pilocarpine-induced status epilepticus model. HW designed the experiment.

\section{Ethics approval and consent to participate}

The present study has been approved by the Institutional Ethical Review Boards of the Shengjing Hospital of China Medical University.

\section{Patient consent for publication}

Not applicable.

\section{Competing interests}

The authors declare that they have no competing interests.

\section{References}

1. Richter Z, Janszky J, Sétáló G Jr, Horváth R, Horváth Z, Dóczi T, Seress L and Ábrahám H: Characterization of neurons in the cortical white matter in human temporal lobe epilepsy. Neuroscience 333: 140-150, 2016.

2. Santini E and Klann E: Genetically dissecting cortical neurons involved in epilepsy in angelman syndrome. Neuron 90: 1-3, 2016.

3. Sharop BR, Boldyriev OI, Batiuk MY, Shtefan NL and Shuba YM: Compensatory reduction of Cav3.1 expression in thalamocortical neurons of juvenile rats of WAG/Rij model of absence epilepsy. Epilepsy Res 119: 10-12, 2016.

4. Woodbury DM: Neurotransmitters and epilepsy: Distinguishing characteristics and unifying precepts. Fed Proc 43: 2529-2531, 1984.

5. Werner FM and Coveñas R: Classical neurotransmitters and neuropeptides involved in generalized epilepsy in a multi-neurotransmitter system: How to improve the antiepileptic effect? Epilepsy Behav 71: 124-129, 2017.

6. Ievglevskyi O, Isaev D, Netsyk O, Romanov A, Fedoriuk M, Maximyuk O, Isaeva E, Akaike $\mathrm{N}$ and Krishtal O: Acid-sensing ion channels regulate spontaneous inhibitory activity in the hippocampus: Possible implications for epilepsy. Philos Trans R Soc Lond B Biol Sci 371: pii: 20150431, 2016.

7. Lerche H, Shah M, Beck H, Noebels J, Johnston D and Vincent A: Ion channels in genetic and acquired forms of epilepsy. J Physiol 591: 753-764, 2013.

8. Heuser K, Szokol K and Tauboll E: The role of glial cells in epilepsy. Tidsskr Nor Laegeforen 134: 37-41, 2014 (In English; Norwegian).

9. Afawi Z, Oliver KL, Kivity S, Mazarib A, Blatt I, Neufeld MY, Helbig KL, Goldberg-Stern H, Misk AJ, Straussberg R, et al: Multiplex families with epilepsy: Success of clinical and molecular genetic characterization. Neurology 86: 713-722, 2016.

10. Vezzani A, Lang B and Aronica E: Immunity and Inflammation in Epilepsy. Cold Spring Harb Perspect Med 6: a022699, 2015.

11. Kim DW, Sunwoo JS and Lee SK: Incidence and localizing value of vertigo and dizziness in patients with epilepsy: Video-EEG monitoring study. Epilepsy Res 126: 102-105, 2016.

12. Kim H, Thurman DJ, Durgin T, Faught E and Helmers S: Estimating epilepsy incidence and prevalence in the US pediatric population using nationwide health insurance claims data. J Child Neurol 31: 743-749, 2016. 
13. Liang $\mathrm{S}$, Zhang J, Zhang $\mathrm{S}$ and $\mathrm{Fu} \mathrm{X}$ : Epilepsy in adults with supratentorial glioblastoma: Incidence and influence factors and prophylaxis in 184 patients. PLoS One 11: e0158206, 2016.

14. Loewen JL, Barker-Haliski ML, Dahle EJ, White HS and Wilcox KS: Neuronal injury, gliosis, and glial proliferation in two models of temporal lobe epilepsy. J Neuropathol Exp Neurol 75: 366-378, 2016.

15. Eid T, Lee TW, Patrylo P and Zaveri HP: Astrocytes and glutamine synthetase in epileptogenesis. J Neurosci Res: Jul 18, 2018 (Epub ahead of print).

16. Hamilton NB and Attwell D: Do astrocytes really exocytose neurotransmitters? Nat Rev Neurosci 11: 227-238, 2010.

17. James LR, Andrews S, Walker S, de Sousa PR, Ray A, Russell NA and Bellamy TC: High-throughput analysis of calcium signalling kinetics in astrocytes stimulated with different neurotransmitters. PLoS One 6: e26889, 2011.

18. Magistretti PJ, Sorg O, Yu N, Martin JL and Pellerin L: Neurotransmitters regulate energy metabolism in astrocytes: Implications for the metabolic trafficking between neural cells Dev Neurosci 15: 306-312, 1993.

19. Sukigara S, Dai H, Nabatame S, Otsuki T, Hanai S, Honda R, Saito T, Nakagawa E, Kaido T, Sato N, et al: Expression of astrocyte-related receptors in cortical dysplasia with intractable epilepsy. J Neuropathol Exp Neurol 73: 798-806, 2014.

20. Carmignoto G and Haydon PG: Astrocyte calcium signaling and epilepsy. Glia 60: 1227-1233, 2012.

21. Mecha M, Carrillo-Salinas FJ, Feliú A, Mestre L and Guaza C: Microglia activation states and cannabinoid system: Therapeutic implications. Pharmacol Ther 166: 40-55, 2016.

22. Ni R, Mu L and Ametamey S: Positron emission tomography of type 2 cannabinoid receptors for detecting inflammation in thecentral nervous system. Acta Pharmacol Sin: Jun 19, 2018 (Epub ahead of print)

23. Rizzo V, Carletti F, Gambino G, Schiera G, Cannizzaro C, Ferraro G and Sardo P: Role of CB2 receptors and cGMP pathway on the cannabinoid-dependent antiepileptic effects in an in vivo model of partial epilepsy. Epilepsy Res 108: 1711-1718, 2014.

24. Hocker SE: Status epilepticus. Continuum (Minneap Minn) 21 (5 Neurocritical Care): 1362-1383, 2015.

25. Xu J: New insights into GFAP negative astrocytes in calbindin D28k immunoreactive astrocytes. Brain Sci 8: pii: E143, 2018.

26. Xu JJ, Diaz P, Bie B, Astruc-Diaz F, Wu J, Yang H, Brown DL and Naguib M: Spinal gene expression profiling and pathways analysis of a CB2 agonist (MDA7)-targeted prevention of paclitaxel-induced neuropathy. Neuroscience 260: 185-194, 2014

27. Molina-Holgado E, Vela JM, Arévalo-Martín A, Almazán G, Molina-Holgado F, Borrell J and Guaza C: Cannabinoids promote oligodendrocyte progenitor survival: Involvement of cannabinoid receptors and phosphatidylinositol-3 kinase/Akt signaling. J Neurosci 22: 9742-9753, 2002.

28. Kim J and Li Y: Chronic activation of CB2 cannabinoid receptors in the hippocampus increases excitatory synaptic transmission. J Physiol 593: 871-886, 2015.
29. Devane WA, Dysarz FA III, Johnson MR, Melvin LS and Howlett AC: Determination and characterization of cannabinoid receptor in rat brain. Mol Pharmacol 34: 605-613, 1988.

30. Jing N, Fang B, Wang ZL and Ma H: Remote ischemia preconditioning attenuates blood-spinal cord barrier breakdown in rats undergoing spinal cord ischemia reperfusion injury: Associated with activation and upregulation of $\mathrm{CB} 1$ and $\mathrm{CB} 2$ receptors. Cell Physiol Biochem 43: 2516-2524, 2017.

31. Seifert G and Steinhäuser C: Neuron-astrocyte signaling and epilepsy. Exp Neurol 244: 4-10, 2013.

32. Viscomi MT, Oddi S, Latini L, Pasquariello N, Florenzano F, Bernardi G, Molinari M and Maccarrone M: Selective CB2 receptor agonism protects central neurons from remote axotomy-induced apoptosis through the PI3K/Akt pathway. J Neurosci 29: 4564-4570, 2009.

33. Duan W, Chen Y and Wang XR: MicroRNA-155 contributes to the occurrence of epilepsy through the PI3K/Akt/mTOR signaling pathway. Int J Mol Med 42: 1577-1584, 2018.

34. Khwanraj K, Madlah S, Grataitong K and Dharmasaroja P: Comparative mRNA expression of eEF1A isoforms and a $\mathrm{PI} 3 \mathrm{~K} / \mathrm{Akt} / \mathrm{mTOR}$ pathway in a cellular model of parkinson's disease. Parkinsons Dis 2016: 8716016, 2016.

35. Zhang W, Liu J, Hu X, Li P, Leak RK, Gao Y and Chen J: n-3 polyunsaturated fatty acids reduce neonatal hypoxic/ischemic brain injury by promoting phosphatidylserine formation and Akt signaling. Stroke 46: 2943-2950, 2015.

36. Roy A, Skibo J, Kalume F, Ni J, Rankin S, Lu Y, Dobyns WB, Mills GB, Zhao JJ, Baker SJ and Millen KJ: Mouse models of human PIK3CA-related brain overgrowth have acutely treatable epilepsy. Elife 4: pii: e12703, 2015.

37. Hester MS, Hosford BE, Santos VR, Singh SP, Rolle IJ, LaSarge CL, Liska JP, Garcia-Cairasco N and Danzer SC: Impact of rapamycin on status epilepticus induced hippocampal pathology and weight gain. Exp Neurol 280: 1-12, 2016.

38. Lasarge CL and Danzer SC: Mechanisms regulating neuronal excitability and seizure development following mTOR pathway hyperactivation. Front Mol Neurosci 7: 18, 2014.

39. Bateup HS, Denefrio CL, Johnson CA, Saulnier JL and Sabatini BL: Temporal dynamics of a homeostatic pathway controlling neural network activity. Front Mol Neurosci 6: 28, 2013.

40. Berdichevsky Y, Dryer AM, Saponjian Y, Mahoney MM, Pimentel CA, Lucini CA, Usenovic M and Staley KJ: PI3K-Akt signaling activates mTOR-mediated epileptogenesis in organotypic hippocampal culture model of post-traumatic epilepsy. J Neurosci 33: 9056-9067, 2013.

41. Groszer M, Erickson R, Scripture-Adams DD, Lesche R, Trumpp A, Zack JA, Kornblum HI, Liu X and Wu H: Negative regulation of neural stem/progenitor cell proliferation by the Pten tumor suppressor gene in vivo. Science 294: 2186-2189, 2001.

42. Su CH, Lan KH, Li CP, Chao Y, Lin HC, Lee SD and Lee WP: Phosphorylation accelerates geldanamycin-induced Akt degradation. Arch Biochem Biophys 536: 6-11, 2013.

43. Liao Y and Hung MC: Physiological regulation of Akt activity and stability. Am J Transl Res 2: 19-42, 2010. 